\title{
Can Any Country Afford to Snub Chinese Tourists?
}

\author{
Maria Boyd \\ mariaboyd@me.com
}

China outbound tourism industry has come a long way since 1997 when a handful of selected Asian countries were given "Approved Destination Status" (ADS) whereby the Chinese people could travel to these specific countries in groups.

This marked the initial boost to China outbound tourism that had been initiated in 1983 when the Chinese citizens were allowed to visit relatives living in Hong Kong, Macau and other South-East Asian countries under the condition that their hosts (family relatives) had to pay for the entire stay and for their travelling expenses.

\section{Staggering Outbound Tourism Figures}

Over the past 13 years, the effects of the rapid economic expansion of the Chinese economy has been staggering and have generated enormous changes, turning tourism into a major economic sector in China. Today, the outbound tourism industry is included in the "Chinese National Development Strategy Frameworks". It is strongly supported by the government as it shows valuable impacts such as improving China's international image, spreading Chinese culture, enhancing foreign perception of China, promoting better understanding of the foreign cultures by the Chinese citizens and easing possible trade tensions.

As a consequence, no restriction on overseas travel is expected to take place in the years ahead and on the contrary, further development is expected. The key feeders are the loosening of China's outbound tourism policies, the ever increasing number of countries granted ADS, the expected continuous high economic growth of the country and the strengthening of the Chinese currency.

These factors are leading the Chinese tourism experts to forecast a steady average annual growth rate of China outbound tourists at around $10 \%$ year-on-year over the next 10 years. The gradual entry of foreign travel agencies in the Chinese market resulting in the implementation of higher service quality standards across the industry is also expected to boost outbound travel.

During the period 2005-2009, the number of Chinese outbound tourists jumped from 31 million to 47.7 million, an increase of 16.7 million or $+53.9 \%$. According to the China Tourism Academy (CTA), 53 to 54 million Chinese travellers will go 
abroad in 2010 and the number of outbound tourists should be in the following range over the next 10 years:

- 2010 53-54 million

- $2015 \quad 75-80$ million

- 2020 100-110 million

As such, China is expected to become the world's fourth largest outbound market in 2020.

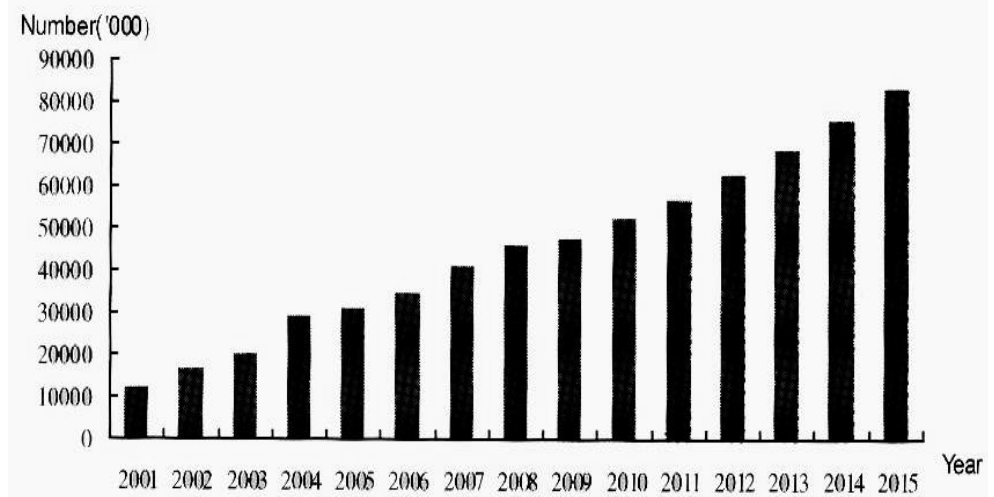

Source: Chinese Outbound Tourism Express 2010

Composition of Chinese outbound travel to foreign countries by region (20082009)

\begin{tabular}{|l|}
\hline Europe \\
$\square$ Americas \\
$\square$ Oceania \\
$\square$ Africa \\
$\square$ Asia \\
\hline
\end{tabular}

Europe $16 \%$

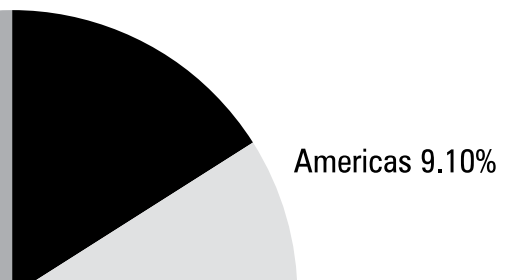

Asia $66.70 \%$

Africa $3.00 \%$ 


\section{The World's Biggest Tourist Spenders}

According to ACNielsen surveys, the Chinese tourists have become the world's biggest spenders on shopping during foreign trips since 2007 overtaking the Japanese and the Americans.

Here again, the figures are staggering. According to New York Tourism Board's China office, some 1,200 Chinese tourists celebrated the Spring Festival in New York between February 14 and 20 year, spending an estimated US\$ 6 million during their trip or an average of US\$ 5,000 per person excluding travel, transportation and full board.

Official figures compiled by FULL FORM (UNWTO) - from China's balance of payments' data and the International Monetary Fund reveal that the average annual increase of spending is over 10\% per annum since 2000 (as measured in US\$). In 2009, the Chinese tourists splashed out US\$ 43.7 billion on their travel abroad and ranked fourth in the world as top spending nations on international tourism lagging behind Germany, the US and the UK. This actually marks a $21 \%$ increase versus 2008 when the overall spending reached US\$ 36.2 billion.

Luxury goods are an important part of Chinese tourists' shopping spree and according to the "China Luxury Forecast" released by Ruder Finn Asia and market research institution Albatross Global Solutions on July 22, 2010, the economic crisis affecting the rest of the world has limited impact on Chinese luxury consumers, with $40 \%$ of them planning to spend the same amount of money as they did in 2009 , and another $38 \%$ of shoppers expecting to spend more.

\section{Continuous Growth Irrespective of Economic \& Travel Uncertainties}

Despite the global financial crisis and influenza H1N1 scare, the Chinese outbound market remained resilient in 2009 with the number of Chinese outbound travellers reaching 47.66 million (4\% increase versus 2008), the highest ever number and a nine-fold increase from 1995 when around 5 million Chinese travelled overseas.

The 2010 Visa and Pacific Asia Travel Association (PATA) Asia Pacific Travel Intentions Survey released on July 8, 2010 reveals that the mainland Chinese travellers are planning for 7.4 business and leisure trips in the next two years. The results also show that the Greater China travellers are less affected by the economic climate than last year. This year, $50 \%$ of the respondents said they will travel irrespective of economic uncertainties.

However, the Chinese tourists are increasingly concerned about security issues and events like political turmoil in Thailand, repeat bombing attacks in Indonesia or terrorist threats in India have a direct negative impact on the growth of Chinese outbound tourism to these countries. 


\section{Increased sophistication}

Chinese outbound tourists are becoming more discerning and sophisticated and therefore it influences their preference towards more individualized and customized travel experiences, a greater variety of products and flexibility in terms of catering needs. The concept of leisure and relaxation is now shared by a growing number of travellers, which explains the growing success of wellness and spas. Quality tours are also on the rise for the Chinese upper class with first class travel, fine dining, international hotel brands, spas, golf, horse riding/polo, yachting and other fun-filled activities.

The year 2010 was designated as the "Theme Year of Quality Upgrading for Tourism Services" and a new set of policies and regulations were issued by the China National Tourism Administration (CNTA) to this respect. The China Association of Travel Services also launched "China Outbound Tourism Quality Service Certification Program" (QSC Program) for its members.

While in the 1990s, when the consumers tended to follow the footsteps of others (visiting places that their friends or relatives had already visited) or went for well-known destinations (at that time, mostly Asian countries), today, travellers are eager to set the trend and to discover new destinations. As such, the list of new ADS countries is eclectic and reflects this trend with, for example, countries like Guyana, Ecuador, the Dominican Republic, Cape Verde, Papua New Guinea, Montenegro and Uzbekistan.

The concepts of experience and knowledge are also increasingly important for repeat outbound travellers. While visiting four to five countries in eight to ten days used to be popular 10 years ago, today a larger number of Chinese outbound tourists want in-depth tours enabling them to know more about each country they visit and covering several angles with qualified guides/escorts to have a meaningful experience.

\section{Larger FIT Business}

The number of (FIT) travellers is on the increase and people in their mid thirties to mid forties form the core of this group. They are Internet savvy and use social networking sites to decide on a destination. Initially most FITs were either going to Hong Kong and Macau or to Asian countries. Today, the Chinese FITs travel globally. It must be noted that the FITs were expected to represent $50 \%$ of outbound travellers originating from Shanghai in 2010 (from over $46 \%$ in 2009), which shows the increasing importance of these travellers in the years ahead.

This audience is creating new tourism segments that were untapped several years ago such as cruises, exotic island vacation or religious tourism. Nowadays, the big players in the cruise business such as Carnival, Royal Caribbean, Star Cruise and MSC have all established branches in Shanghai. Together with the locally-based companies, they have started developing regional cruise tours with Shanghai as the home port using newly-constructed facilities like the International Passenger 
Transport Centre of Shanghai Port and the Wusongkou Cruise Wharf. It must be noted that this trend is also influencing domestic tourism products. On the Yangtze River, new luxury liners are being introduced to cater to the domestic and international markets.

Similarly, small and previously little-known-in-China islands are now recording high annual growth rates with, for example, an increase of $50 \%$ in Chinese visitors to Papua New Guinea, a rise of $44 \%$ to Tahiti and $23 \%$ to Tonga.

Finally, over the past five years, religion and culture travel has steadily increased with the loosening of the Chinese state control on religious matters. It focuses strongly on sites listed on the United Nations Educational, Scientific and Cultural Organization (UNESCO) World Heritage List and on spiritual places of major interest such as Lumbini in Nepal or Bodh Gaya in India.

\section{The Chinese Super Rich}

A new social class has also emerged over the past 15 years as a result of the economic boom the China's "super-rich". According to the 2010 Hurun Wealth Report published in April 2010, there are 875,000 people with a personal wealth of more than RMB 10 million (over US\$ 1.5 million), which marks a growth of $6.1 \%$ on the previous year. According to the report, wealthy Chinese take an average of 16 days holiday and three foreign trips per year, and are developing distinctive tastes.

In 2009 , this particular segment bought $27.5 \%$ of the world luxury goods for a total of US\$ 9.4 billion, according to the World Luxury Association. Today, China is the second largest consumer of luxury goods market after Japan and is expected to become the leading market within the next five years (by 2015) reaching US\$ 14.6 billion, according to the Chinese Academy of Social Sciences, or $29 \%$ of the world's market for luxury goods.

The latest "Super Toys" of interest to the top bracket Chinese multi-millionaires are private jets with a 25\% increased estimated sales in 2010 versus 2009 and luxury yachts considering the 64 yachting clubs and marinas in China.

\section{What Next?}

It is no surprise to notice that countries eager to substantially increase their shares of the Chinese outbound market are taking dramatic steps such as the implementation of relaxed visa requirements for the Chinese tourists and the introduction of one-year multiple entry-visa open to a larger range of new applicants. Similarly, the opening of "integrated" resorts in Singapore including casinos is a complete reverse to the City-State previous policy on gambling operations within the country. 
Time will tell which countries benefit most from the Chinese tourist bonanza in the years ahead but Asian nations will, in any case, take the lion's share. Over the first six months of this year, the current growth momentum of arrivals from China to the Asia Pacific region is estimated to have grown by $30 \%$ and could reach 45 million for the full year.

In 2010, Taiwan and Singapore were expected to join the "one-million arrivals from Chinese mainland" club that presently only includes Japan, South Korea, and Malaysia. The current members are working hard at keeping their lead and Japan, before the current political tension with China, was expected to spend up to a quarter of its 2010 annual tourism promotional budget on the China market alone with 1.5 million Chinese travellers expected in 2010 and as much as 6 million to visit the country annually in or before 2020 .

\section{References}

Annual Report of China Outbound Tourism Development [2009/2010], China Tourism Academy

China Daily/Outbound Tourism Updates [01-10/2010]

China Daily/UNWTO International Travel Report [ 04/30/2010]

China Daily/Luxury Brands Update [ 07/22/2010]

China Luxury Forecast, Albatross Global Solutions \& Ruder Finn Asia

CNTA Yearbook of China Tourism Statistics [2009]

CNTA $11^{\text {th }}$ five-year Plan for the China Tourism Industry

China National Tourist Office, China Tourism Statistics [2009]

Chinese Outbound Tourism Express [2010]

Chinese Outbound Travel Market, UNWTO and EU Travel Commission Hurun Wealth Report [2010]

PATA Asia Pacific Tourism Data for 2009

PATA Asia Pacific Tourism Forecasts for 2010

PATA Asia Pacific / AC Nielson Survey on China Outbound Tourism [2009]

PATA and China Outbound Tourism Research Institute Report on Outbound Tourism [2009]

Shanghai Municipal Government Tourism Office 2009 Survey on tours undertaken by Shanghai residents

State Statistical Bureau Statistics [2009-2010]

UNWTO, The Chinese Outbound Market [2009]

Visa and Pacific Asia Travel Association (PATA) Asia Pacific Travel Intentions Survey [2010] 